\title{
INFLUENCE OF PARTICLE SIZE AND SIZE DISTRIBUTION ON KINETIC MECHANISM OF SPRUCE BARK POLYPHENOLS EXTRACTION
}

\author{
OANA ALEXANDRA PĂTRĂUȚANU, LILIANA LAZĂR, \\ VALENTIN I. POPA and IRINA VOLF
}

\author{
"Gheorghe Asachi" Technical University of Iasi, "Cristofor Simionescu” Faculty of Chemical Engineering \\ and Environmental Protection, 73 Prof. Dimitrie Mangeron Str., 700050, Iasi, Romania \\ \Corresponding authors: L. Lazar, lillazar@ch.tuiasi.ro, I. Volf, iwolf@ch.tuiasi.ro
}

Received August 12, 2018

\begin{abstract}
This paper presents the influence of spruce bark (Picea abies) particle size and size distribution on the separation of polyphenols, using a green extraction process (ultrasound-assisted extraction - UAE), in order to highlight the kinetic mechanism. Experiments were performed at $50{ }^{\circ} \mathrm{C}$, for 45 minutes, using ethanol-water $(70 \% \mathrm{v} / \mathrm{v})$ as solvent. The considered particle size fractions were: $0.25,0.315,0.4,0.5,0.63$ and $1 \mathrm{~mm}$. The crude extracts were assessed using the Folin Ciocalteu method for total polyphenols content (TPC) and high-performance thin layer chromatography (HPTLC) for identifying simple phenolic acids and tannins. The study points out that particle size significantly influences the UAE process in terms of separated polyphenols and kinetic mechanism as well. From the particles with the lowest size, the highest amounts of simple phenolic acids (sinapic acid, p-coumaric acid) and tannins (catechin) were obtained. Extraction kinetics was estimated using a second order model. Results showed a good prediction of this model for the extraction kinetics in all the experiments $\left(R^{2}>0.911\right)$, which gave the possibility to estimate the concentration of polyphenols at saturation $\left(\mathrm{C}_{\mathrm{s}}\right)$, the rate constant $(\mathrm{k})$ and the initial rate $(\mathrm{h})$. All these parameters were affected by the particle size and size distribution of spruce bark.
\end{abstract}

Keywords: spruce bark, polyphenols, ultrasound-assisted extraction, particle size, diffusion, kinetics

\section{INTRODUCTION}

The wood bark of forest species, resulting as a solid waste from wood processing, represents an important feedstock that is currently an undervalorised resource. The wood bark is rich in fine chemicals that could be used in various fields, from the pharmaceutical one - as bioactive compounds - to green polymers and bio-based materials.

The valorisation of bark is appropriate due to its large amounts released as residues from forestry and wood processing, but mainly considering its important chemical composition. In recent years, the interest in extracting fine chemicals, especially polyphenols, has increased due to their valuable biological properties, ${ }^{1,2}$ the latter being known as natural antioxidants with proven effects on human health, anti-allergic, anti-inflammatory and antimicrobial action, helpful in the prevention of cardiovascular, neurological and even tumoral diseases. ${ }^{3-6}$ Also, polyphenols have an important influence on microorganisms $^{7}$ and on plant growth and development. ${ }^{8-11}$

In order to obtain bioactive compounds of high quality and quantity, the bark is subjected to an extraction process, depending on some parameters (solvent, solvent-to-solid ratio, extraction time, temperature). ${ }^{12,13}$ The extraction method must be simple, fast, economic and with large applicability. Conventional extraction techniques have the drawback of leaving trace amounts of solvents or causing possible thermal degradation.

Some nonconventional methods, which are more environmentally friendly due to decreased use of chemicals, reduced operational time, better yield and better extract quality have been developed. The ultrasound-assisted extraction (UAE), microwave-assisted extraction (MAE) and supercritical fluid extraction (SFE) are the most widely used and have been critically reviewed in the last decade. ${ }^{14-19}$

Besides the extraction technique and the 
specific parameters, particle size also affects the extraction yield. Size reduction of biomass before extraction offers greater surface area for mass transfer, which enhances the diffusion of active principles into the solvent. The solid particle is assumed to be a pseudo-homogeneous matrix of spherical geometry with radius or a thin plate. In the literature, there are insufficient data on the influence of spruce bark particle size and size distribution on polyphenols separated using the ultrasound-assisted extraction. ${ }^{20}$

In this context, the aim of this work has been to clarify the influence of particle size and size distribution of Picea abies bark on the extraction of polyphenols, using the ultrasound-assisted process, in order to understand and highlight the kinetic mechanism. Therefore, the experimental part involved two steps: the first consisted in a preliminary study of kinetic models depicted in the literature regarding the extraction process, while in the second one, the extraction of polyphenols was interpreted using a second-order kinetic model to predict the extraction constant rate, the concentration of the target compounds at saturation and the initial constant rate.

\section{EXPERIMENTAL}

\section{Material and sample preparation}

The feedstock represented by spruce (Picea abies) bark was provided as solid waste from a wood processing plant. Prior to extraction, the bark was dried under normal aeration conditions. After drying, the spruce bark was milled in GrindoMix GM 2000 equipment and mechanically separated using a vibratory system with six standard sieves $(0.25,0.315$, $0.4,0.5,0.63,1 \mathrm{~mm})$. After grinding, the samples were immediately vacuum packed and stored at $20{ }^{\circ} \mathrm{C}$ until extraction. For the experiments, all the fractions were used.

\section{Methods}

The Laboratory Analytical Procedures for standard biomass analysis (NREL) were followed for spruce bark characterisation. ${ }^{21}$ For all the experiments, the bark had $8.8 \%$ moisture and $1.8 \%$ ash content.

\section{Ultrasound-assisted extraction}

The extraction of polyphenols was carried out with ethanol-water (70\% v/v) as solvent, using a Sonorex RK $100 \mathrm{H}$ ultrasonic thermostatic bath (Bandelin Electronic GmbH \& Co. KG, Berlin, Germany). The experimental set-up is depicted schematically in Figure 1.
The ultrasound-assisted extraction process was carried out according to the following protocol: ${ }^{18} 5 \mathrm{~g}$ of spruce bark was loaded in a $250 \mathrm{~mL}$ flat-bottom flask containing $50 \mathrm{~mL}$ of solvent. The flask was placed in the ultrasonic thermostatic bath operating at $35 \mathrm{kHz}$ frequency and $320 \mathrm{~W}$ power. The temperature was controlled and maintained at $25{ }^{\circ} \mathrm{C}$ and $50{ }^{\circ} \mathrm{C}$, respectively $\left( \pm 1{ }^{\circ} \mathrm{C}\right)$. The bark/solvent ratio was $1: 10$ $(\mathrm{w} / \mathrm{v})$. The particle size influence on the process and, especially, on kinetic aspects was studied for different exposure time $(5,10,20,30,45,60$ and 75 minutes).

Afterwards, the crude ethanol extracts were separated using a Hettich Rotofix 32 centrifuge (at $4000 \mathrm{rpm}$ for $4 \mathrm{~min}$ ), while the supernatant was carefully collected and used for further analyses as described below.

\section{Determination of total polyphenols content}

The total polyphenols content (TPC) was determined using the Folin-Ciocalteu method. ${ }^{22}$

Results were expressed as milligrams gallic acid equivalents (GAE) per gram of dry spruce bark weight (TPC, mg GAE $\mathrm{g}^{-1}$ ), calculated as follows Equation (1):

$\mathrm{TPC}=\frac{\mathrm{C}_{\mathrm{GAE}} \cdot \mathrm{V}}{\mathrm{m}}$

where $C_{G A E}$ is the concentration of total polyphenols ( $\mathrm{mg}$ GAE $\mathrm{mL}^{-1}$ ) at a given extraction time, $V$ is the volume of the extract $(\mathrm{mL})$ and $m$ the dry spruce bark weight $(\mathrm{g})$.

\section{Identification of polyphenols using High- Performance Thin-Layer Chromatography (HPTLC)}

The HPTLC assay was performed according to Patil and collaborators, ${ }^{23}$ as well as Tebrencu and collaborators, ${ }^{24}$ using a CAMAG LINOMAT IV TLC 3 Scanner and WINCATS Planar Chromatography Manager software. A HPTLC plate G60 F254, 200 x $100 \mathrm{~mm}$ (Merck, Darmstadt, Germany) saturated in methanol was used as stationary phase for identifying phenolic acids and tannins.

For simple phenolic acid identification, the length of the band was $8 \mathrm{~mm}$, the application rate of $8 \mu \mathrm{L} / \mathrm{s}$ and the application volume of $6 \mu \mathrm{L}$ for samples and of $3 \mu \mathrm{L}$ for standards. The plates were examined at 254 and $366 \mathrm{~nm}$, before and after spraying with homogenized reagents (followed by air drying). The mobile phase used was toluene:ethyl acetate:formic acid in a 12.5:10:1.25 v/v/v ratio. A NP $1 \%$ methanol solution + PEG 400 ethanol solution was used for spraying the plate, followed by heating at $100{ }^{\circ} \mathrm{C}$ for $10 \mathrm{~min}$. The analysis was performed in an airconditioned room at $22{ }^{\circ} \mathrm{C}$. 
Polyphenols

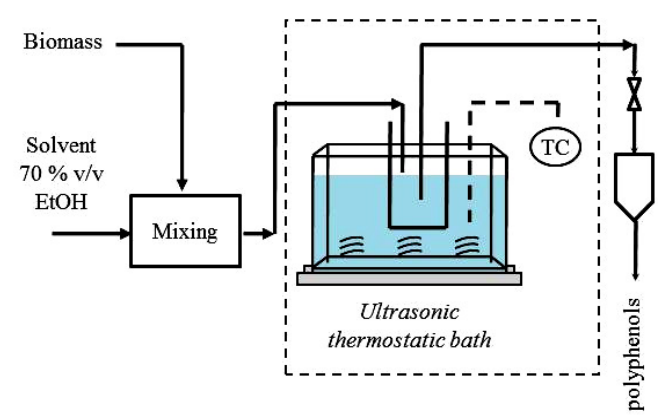

Figure 1: Experimental set-up for ultrasound-assisted extraction

For tannins, the procedure was similar, except that an application volume of $10 \mu \mathrm{L}$ was used for samples and of $5 \mu \mathrm{L}$ for standards. The mobile phase used in this case was toluene:ethyl acetate:formic acid in a ratio of 12:12:2 (v/v/v). A 5\% ethanol ferric chloride solution was used for spraying the plate, followed by heating at $100{ }^{\circ} \mathrm{C}$ for 10 minutes.

\section{Kinetic model}

The determination of kinetic parameters is the most important step in order to design an efficient solidliquid extraction process of polyphenols from spruce bark.

The solid-liquid extraction models include unsteady diffusion, film theory, Fick's law of diffusion, rate law and Peleg's model. ${ }^{25-27}$ According to the literature, the decrease in particle size and the increase in solvent to solid ratio enhance the diffusivity of Fick's law derivative models, as well as the initial extraction rate $(h)$ and the extraction constant rate $(k)$ law models, predominantly. ${ }^{25,27,28}$

For extracting spruce bark polyphenols using the ultrasound-assisted extraction process, a second-order rate law gives the best fits for the extraction rate. ${ }^{18}$ The dissolution rate of active compounds into the extraction solvent is given in Equation (2):

$\frac{\mathrm{dC}_{\mathrm{t}}}{\mathrm{dt}}=\mathrm{k}\left(\mathrm{C}_{\mathrm{s}}-\mathrm{C}_{\mathrm{t}}\right)^{2}$

where $k$ is the second-order extraction rate constant $\left(\mathrm{mL} \mathrm{g}^{-1} \mathrm{~min}^{-1}\right), \quad C_{t}$ is the concentration of total polyphenols (mg GAE $\mathrm{mL}^{-1}$ ) at a given extraction time $\mathrm{t}$ (min), $C_{s}$ is the concentration of total polyphenols ( $\mathrm{mg} \mathrm{GAE} \mathrm{mL}^{-1}$ ) at saturation in the crude extract.

Considering the initial and boundary conditions as $t=0$ to $t$ and $C_{t}=0$ to $C_{t}$, the integrated rate law can be obtained (Eq. (3)):

$\mathrm{C}_{\mathrm{t}}=\frac{\mathrm{C}_{\mathrm{s}}^{2} \cdot \mathrm{k} \cdot \mathrm{t}}{1+\mathrm{C}_{\mathrm{s}} \cdot \mathrm{k} \cdot \mathrm{t}}$

The constant rate $k$ can be determined by fitting the linear transformation of Equation (3) with experimental data, using Equation (4):
$\frac{\mathrm{t}}{\mathrm{C}_{\mathrm{t}}}=\frac{1}{\mathrm{k} \cdot \mathrm{C}_{\mathrm{s}}^{2}}+\frac{\mathrm{t}}{\mathrm{C}_{\mathrm{s}}}$

The concentration of total polyphenols in the extraction solvent at any time can be described by Equation (5):

$$
\mathrm{C}_{\mathrm{t}}=\frac{\mathrm{t}}{(1 / \mathrm{h})+\left(\mathrm{t} / \mathrm{C}_{\mathrm{s}}\right)}
$$

where $h$ is the initial extraction rate $\left(\mathrm{g} \mathrm{mL}^{-1} \mathrm{~min}^{-1}\right)$ when the extraction time $t$ approaches zero.

The initial extraction rate $(h)$, the concentration of total polyphenols at saturation $\left(C_{s}\right)$ and the secondorder extraction constant rate $(k)$ can be determined experimentally from the slope and intercept by plotting $t / C_{t}$ vs. $t$.

\section{Data analysis}

All the experiments were conducted in triplicate. The results were expressed as a mean \pm standard deviation (SD) for $\mathrm{n}=3$. Graphical plots were performed using Microsoft Excel 2010, representing the average of at least three measurements with a relative standard deviation (RSD) lower than $4.5 \%$.

\section{RESULTS AND DISCUSSION}

The spruce bark pre-treated to $8.8 \%$ moisture and $1.8 \%$ ash content was subjected to particle size analysis. All the samples were sieved to determine particle size distribution by weight. The results were presented in Figure 2.

The granulometric distribution assay allowed calculating the medium diameter of the particles with Equation (6).

$$
\left(\mathrm{d}_{\text {med }}\right)_{\text {biomass }}=\frac{1}{\sum_{\mathrm{i}} \frac{\mathrm{x}_{\mathrm{i}}}{\left(\mathrm{d}_{\text {med }}\right)_{\mathrm{i}}}}
$$

where $x_{i}$ is the mass fraction of bark remaining on sieve $i$ and $\left(d_{m e d}\right)_{i}$ is the medium diameter of particles on sieve $i$.

Thus, the value of medium diameter for granulometric classes ranging from 0 to $1.25 \mathrm{~mm}$ is equal with $0.327 \mathrm{~mm}$. 

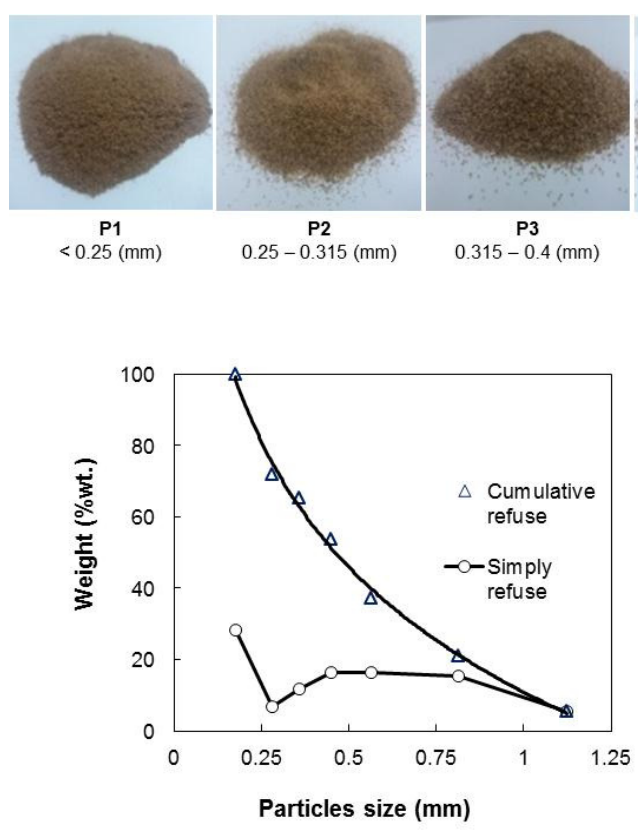

(b)

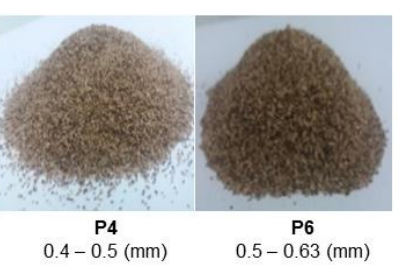

(a)
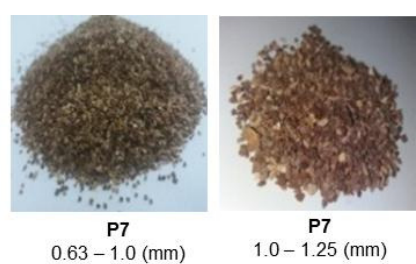

$0.63-1.0(\mathrm{~mm})$

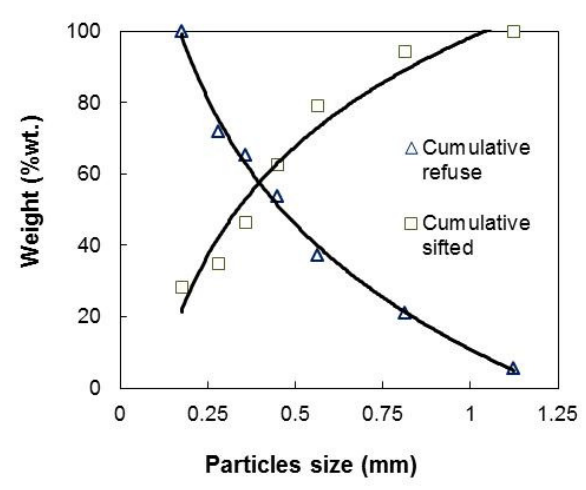

(c)

Figure 2: Granulometric classes of spruce bark samples established by sieving (a) and distribution of particle size curves (b and c) after granulometric analysis

Influence of particle size on ultrasoundassisted extraction of polyphenols

The influence of particle size on the extraction of polyphenols was studied considering the effect of ultrasound irradiation for process intensification. UAE processes were conducted at $50{ }^{\circ} \mathrm{C}$ with a raw material-to-solvent ratio of $1: 10$ $(\mathrm{g} / \mathrm{L})$, extraction time of $45 \mathrm{~min}$ and an aqueous ethanol solution $70 \% \mathrm{v} / \mathrm{v}$. The experiments for fractions from $\mathrm{d}<0.25 \mathrm{~mm}$ up to $\mathrm{d}>1 \mathrm{~mm}$ were depicted in Figure 3.

Under all the studied conditions, a significant positive effect of ultrasound irradiation and, consequently, of temperature was observed. In the UAE process, cavitation and the thermal effect play an important role. The cavitation work, by implosion of bubbles or cavities, and the thermal effect lead to swelling and loosening of the cell structure, resulting in an increased mass transfer of intracellular products to the solvent. ${ }^{28-30}$ At 50 ${ }^{\circ} \mathrm{C}$, both ultrasound and temperature effects were expressed and their combination resulted in a relatively higher extraction of polyphenols.

Particle size is one of the most significant factors affecting the efficiency of extraction, because the particle size controls the kinetics of mass transfer and the access of the solvent to soluble compounds. ${ }^{26,30,31}$ An increase in the extraction rate of total polyphenols was observed with the decrease of particle size. The influence is predictable since the contact surface and the pore diffusion path increase with decreasing particle size, and leads to an easier permeability or diffusivity of the solvent into the material. ${ }^{27,28}$

Figure 3 illustrates a slight increase in TPC extraction rate with the increase in particle size from $0.25-0.315 \mathrm{~mm}$ to $0.63 \mathrm{~mm}$. Small particles may remain at the surface during the extraction process, reducing slightly the extraction efficiency. ${ }^{26,31}$

Higher yields of TPC were obtained for the smallest particle size (lower than $0.25 \mathrm{~mm}$ ). However, when considering a scale-up perspective, this alternative is not recommended because of a very difficult filtration. Thus, particles of $1 \mathrm{~mm}$ can be considered the most suitable for separating spruce bark polyphenols by the ultrasound-assisted extraction process.

A HPTLC assay allowed the identification of seven polyphenols, mainly phenolic acids, such as sinapic acid, p-coumaric acid and tannins: catechin, epicatechin and tannic acid (Table 1). Sinapic acid $(4.2 \mathrm{mg} / 100 \mathrm{~mL}$ extract) and pcoumaric acid $(3.04 \mathrm{mg} / 100 \mathrm{~mL}$ extract) were identified in the largest amount in sample P1. In samples P3, P4 and P5, sinapic acid was 
identified (1.88 mg/100 mL extract) in equal amounts. Catechin and tannic acid were identified in all the samples. The higher amount of catechin (5.13 $\mathrm{mg} / 100 \mathrm{~mL}$ extract) was identified in sample P1, while the largest quantity of tannic acid $(16.40 \mathrm{mg} / 100 \mathrm{~mL}$ extract) was identified in sample P5. Epicatechin (5.35 mg/100 mL extract) was identified in a higher amount in sample P7, followed by (4.72 mg/100 mL extract) sample P1.
The results point out that particle size is a determining factor in the extraction of certain polyphenols. This is a very useful observation that could be useful in the design and operation of extraction processes.

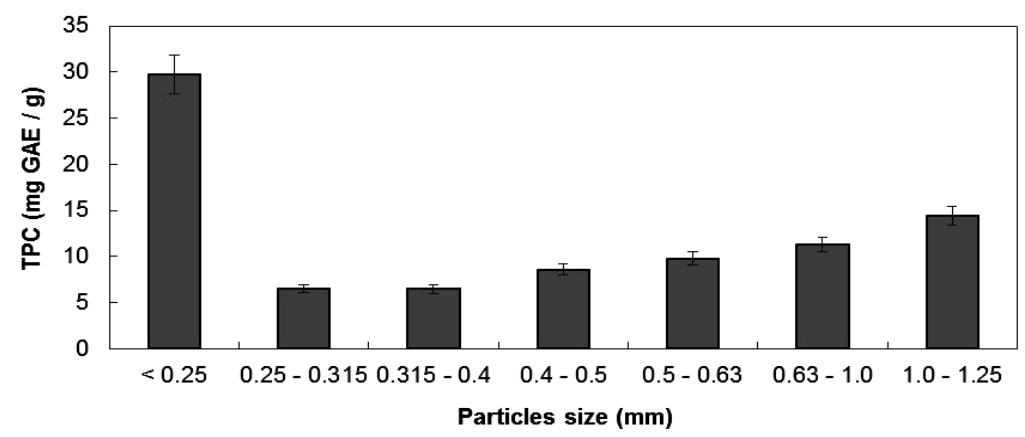

Figure 3: Effect of particle size on TPC separated from spruce bark by ultrasound-assisted extraction (ethanol-water $70 \% \mathrm{v} / \mathrm{v}, \mathrm{S} / \mathrm{L}$ ratio $\left.=1 / 10 \mathrm{~g} / \mathrm{L}, 50{ }^{\circ} \mathrm{C}, 45 \mathrm{~min}\right)$

Table 1

Phenolic compounds identified by HPTLC

\begin{tabular}{cccccc}
\hline \multirow{2}{*}{$\begin{array}{c}\text { Sample } \\
\text { code }\end{array}$} & Sinapic acid & p-Coumaric acid & Catechin & Epicatechin & Tannic acid \\
\cline { 2 - 6 } P1 & 4.2 & 3.04 & 5.13 & 4.72 & 14.03 \\
P2 & 2.61 & 2.12 & 2.81 & 3.42 & 15.89 \\
P3 & 1.88 & 1.67 & - & 2.64 & 11.76 \\
P4 & 1.88 & 1.72 & 3.42 & 2.81 & 14.07 \\
P5 & 1.88 & 1.90 & 3.40 & 3.10 & 16.40 \\
P6 & 2.52 & 2.70 & 4.82 & 4.70 & 15.21 \\
P7 & 2.66 & 2.80 & 4.30 & 5.35 & 12.17 \\
\hline
\end{tabular}

\section{Separation mechanism of polyphenols by} ultrasound-assisted extraction

The kinetics of ultrasound-assisted extraction of polyphenols was assessed using three different particle sizes: $\mathrm{d}<0.25 \mathrm{~mm}, \mathrm{~d}=0.315-0.4 \mathrm{~mm}$ and $d=0.63-1 \mathrm{~mm}$. The influence of particle size on the extraction kinetics is presented in Figure 4.

The extraction process of polyphenols appears to be a typical second-order process taking place in two subsequent stages: the first, from 0 to 15 min, when the major part of the solute is extracted quickly due to the scrubbing and dissolution caused by the driving force of the fresh solvent. Then follows the second stage, which is much slower, and occurs when the solutes transfer through diffusion from the biomass matrix to the solvent. The observation is in accordance with the literature. ${ }^{25,26,32}$

The data included in Table 2 highlight that the concentration of total polyphenols at the saturation point increases exponentially with the increase of particle size, according to Equation (7):

$\mathrm{C}_{\mathrm{s}}=11.159 \cdot \exp (0.3551 \cdot \mathrm{d})$

The validation of Equation (7) was done, by performing the extraction of polyphenols from the whole mix of spruce bark particles presented in Figure 6. Experimental and theoretical data matched very well. Thus, experimental TPC was $12.576 \mathrm{mg} \mathrm{g}^{-1}$, while the calculated one was 
$12.533 \mathrm{mg} \mathrm{g}^{-1}$. The concentration of total polyphenols in the extract from the whole mix of spruce bark is very close to the amount of total polyphenols from the fraction with the particle size between $0.63-1 \mathrm{~mm}$.

The second stage of the second-order kinetic mechanism is decisive: the solutes transfer

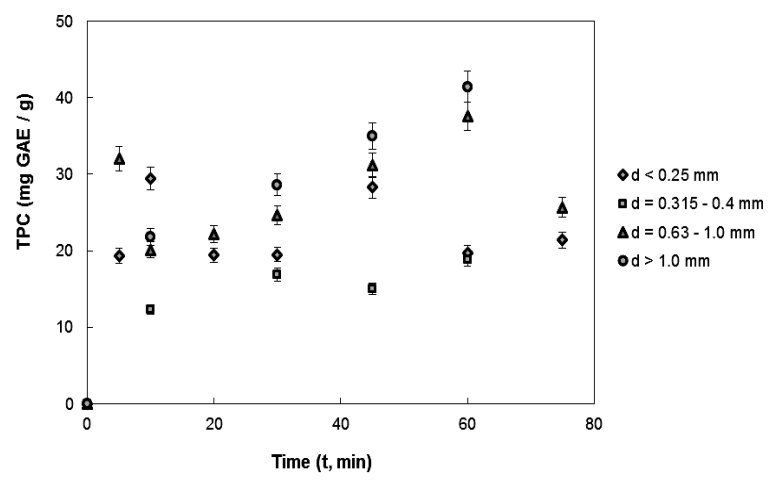

Figure 4: Influence of particle size on extraction of polyphenols from spruce bark (ethanol-water $70 \% \mathrm{v} / \mathrm{v}$, $\mathrm{S} / \mathrm{L}$ ratio $=1 / 10 \mathrm{~g} / \mathrm{L}, 50^{\circ} \mathrm{C}$ ) through diffusion from the biomass matrix to the solvent. The subsequent diffusion in batch type extraction depends on internal and external diffusion. In an ultrasound-assisted extraction, the external mass transfer resistance can be considered negligible.

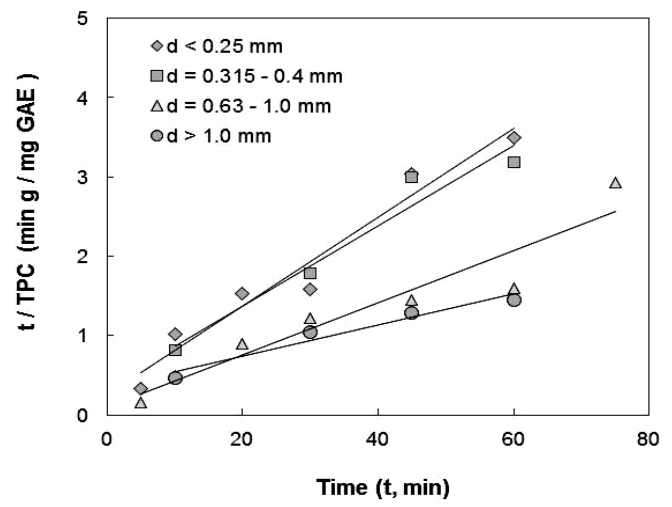

Figure 5: Linearized form of second-order kinetics of TPC extraction for different particle size of spruce bark

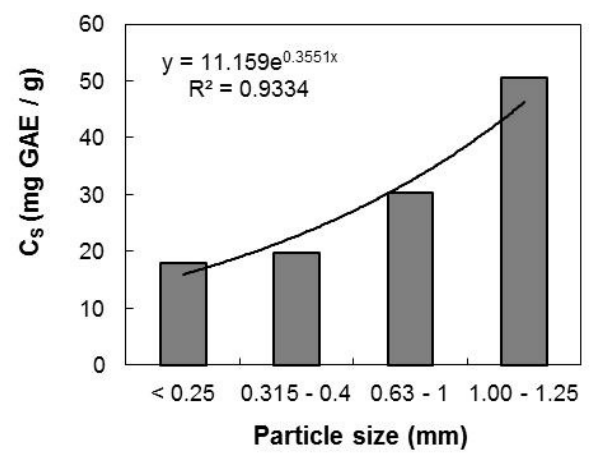

Figure 6: Influence of particle size distribution on concentration of polyphenols at saturation

Table 2

Parameters of second-order kinetics for the extraction of total polyphenols using different particle size of spruce bark

\begin{tabular}{lcccc}
\hline $\mathrm{d}(\mathrm{mm})$ & $\mathrm{C}_{\mathrm{s}}\left(\mathrm{mg} \mathrm{g}^{-1}\right)$ & ${\mathrm{k}\left(\mathrm{g} \mathrm{mg}^{-1} \min ^{-1}\right)} \mathrm{h}\left(\mathrm{mg} \mathrm{g}^{-1} \min ^{-1}\right)$ & $\mathrm{R}^{2}$ \\
\hline$<0.25$ & 17.8571 & 0.0122 & 3.8865 & 0.9565 \\
$0.315-0.4$ & 19.7239 & 0.0072 & 2.8106 & 0.9492 \\
$0.63-1.0$ & 30.3951 & 0.0110 & 10.1523 & 0.9115 \\
$>1.00$ & 50.5051 & 0.0011 & 2.9087 & 0.9487 \\
\hline
\end{tabular}

The internal diffusion of active compounds, as explained in Fick's law, is driven by the difference in concentration between the plant matrix and the bulk solvent. ${ }^{25}$ The concentration of the solute transferred from the sample particle at any time $\left(C_{t}\right)$ can be expressed as in Equations (8) and (9), respectively, based on the non- extracted fraction of the solute in the sample particle $E$ :

$$
\mathrm{E}=1-\frac{\mathrm{C}_{\mathrm{t}}}{\mathrm{C}_{\mathrm{s}}}=\mathrm{A} \cdot \exp (-\mathrm{B} \cdot \mathrm{t})
$$

$\ln \mathrm{E}=\ln \mathrm{A}-\mathrm{B} \cdot \mathrm{t}$

where $C_{s}$ is the total amount of solution transferred after infinite time; $A$ is the model 
constant, and $B$ is the diffusion rate constant and its value has to depend on the geometry of plant samples, shown as follows:

Spherical particles: $\quad B=\frac{\pi^{2} \cdot D}{R^{2}}$
Plate particles: $\quad \mathrm{B}=\frac{\pi^{2} \cdot \mathrm{D}}{4 \cdot \mathrm{L}^{2}}$

where $R$ is the radius of spherical particles, $L$ is length of plate particles, $D$ is diffusion coefficient.

Table 3

Diffusion coefficient of solute for TPC extraction of spruce bark (ethanol $70 \% \mathrm{v} / \mathrm{v}, \mathrm{S} / \mathrm{L}$ ratio $=1 / 10 \mathrm{~g} / \mathrm{L}, 50{ }^{\circ} \mathrm{C}$ and $45 \mathrm{~min}$ )

\begin{tabular}{ccccc}
\hline $\mathrm{A}$ & $\mathrm{B}$ & $\begin{array}{c}\text { Spherical particles } \\
\mathrm{D}\left(\mathrm{m}^{2} \mathrm{~s}^{-1}\right)\end{array}$ & $\begin{array}{c}\text { Plate particles } \\
\mathrm{D}\left(\mathrm{m}^{2} \mathrm{~s}^{-1}\right)\end{array}$ & $\begin{array}{c}\text { Regression } \\
\text { coefficient }\end{array}$ \\
\hline 8.5591 & 0.2257 & $1.717 \cdot 10^{-8}$ & $6.867 \cdot 10^{-8}$ & 0.9329 \\
\hline
\end{tabular}

After mathematical processing of the experimental data and the graphic representation in specific coordinate $\ln \mathrm{E} v s .1 / \mathrm{R}^{2}$ for the constant value of time equal to $45 \mathrm{~min}$, the diffusion coefficient of the solute $(D)$ for the extraction of polyphenols from spruce bark is obtained (Table 3 ).

This study reveals valuable findings on the extraction of polyphenols, i.e. accurate information on spruce bark particle size could lead to better yields of extraction.

\section{CONCLUSION}

Waste spruce bark is an available and valuable source of extractives, especially polyphenols (simple phenolic acids, such as sinapic acid and pcoumaric acid, as well as tannins: catechin, epicatechin and tannic acid) and must be considered for complex processing.

Ultrasounds can be used to increase the performance of polyphenols extraction. In ultrasound-assisted extraction, the particle size influences the yield of the process and, more importantly, the type of polyphenols separated.

The separation of spruce bark polyphenols using the ultrasound-assisted extraction process follows the second-order kinetic mechanism. Furthermore, model parameters, such as saturation concentration $\left(C_{s}\right)$, extraction rate constant $(k)$ and initial rates of extraction $(h)$, were calculated and formulated as a function of the operating factors. These results could be of great interest for a scale-up of the valorisation process.

ACKNOWLEDGMENT: The authors acknowledge the Plantavorel SA Research and Processing Centre for Medicinal Plant, Piatra
Neamt, Romania, for their kind help with the HPTLC assays.

\section{REFERENCES}

1 V. I. Popa and I. Volf, in "Biomass as Renewable Raw Material to Obtain Bioproducts of High-Tech Value", edited by V. I. Popa and I. Volf, Elsevier, 2018, pp. 113-160.

2 I. Ignat, D. G. Radu, I. Volf, A. I. Pag and V. I. Popa, Cellulose Chem. Technol., 47, 387 (2013), http://www.cellulosechemtechnol.ro/pdf/CCT56(2013)/p.387-399.pdf

3 V. I. Popa, M. Dumitru, I. Volf and N. Anghel, Ind. Crop. Prod., 27, $144 \quad$ (2008), https://doi.org/10.1016/j.indcrop.2007.07.019

4 M. E. García-Pérez, M. Royer, G. Herbette, Y. Desjardins, R. Pouliot et al., Food Chem., 135, 1173 (2012), doi: 10.1016/j.foodchem.2012.05.050

O. C. Bujor, A. I. Tălmaciu, I. Volf and V. I. Popa, Tappi J., 4, 187 (2015).

6 I. Spiridon, Cellulose Chem. Technol., 52, 543 (2018), http://www.cellulosechemtechnol.ro/pdf/CCT78(2018)/p.543-550.pdf

A.-R. Hainal, I. Ignat, I. Volf and V. I. Popa, Cellulose Chem. Technol., 45, 211 (2011), http://www.cellulosechemtechnol.ro/pdf/CCT34(2011)/p.211-219.pdf

8 I. Volf, A. Stîngu and V. I. Popa, Environ. Eng. Manage. J., 11, 487 (2012).

9 I. Volf, I. Ignat, M. Neamtu and V. I. Popa, Chem. Pap., 68, 121 (2014), https://doi.org/10.2478/s11696013-0417-6,

${ }^{10}$ C. Tanase, I. Volf, S. Vintu, R. Gradinaru and V. I. Popa, Cellulose Chem. Technol., 47, 553 (2013), http://www.cellulosechemtechnol.ro/pdf/CCT78(2013)/p.553-563.pdf

${ }_{11}$ N. C. Anghel, Cellulose Chem. Technol., 50, 9 (2016), http://www.cellulosechemtechnol.ro/pdf/CCT910(2016)/p.967-971.pdf 
12 J. A. Michiels, C. Kevers, J. Pincemail, J. O. Defraigne and J. Dommes, Food Chem., 130, 986 (2012), doi:10.1016/j.foodchem.2011.07.117

13 S. A. Makanjuola, Food Sci. Nutr., 5, 1179 (2017), doi: 10.1002/fsn3.509

14 J. Azmir, I. S. M. Zaidul, M. M. Rahman, K. M. Sharif, A. Mohamed et al., J. Food Eng., 117, 426 (2013), 10.1016/j.jfoodeng.2013.01.014

15 A. Khoddami, M. Wilkes and T. H. Roberts, Molecules, $\quad \mathbf{1 8}, 2328 \quad$ (2013), https://doi.org/10.3390/molecules 18022328

16 R. E. Ghițescu, I. Volf, C. Cărăușu, A. M. Bühlmann, I. A. Gîlcă et al., Ultrason. Sonochem., 22, 535 (2015), doi: 10.1016/j.ultsonch.2014.07.013

17 A. Talmaciu, I. Volf and V. I. Popa, Chem. Biodivers., 12, $1635 \quad$ (2015), doi: 10.1002/cbdv.201400415.

18 L. Lazăr, A. I. Talmaciu, I. Volf and V. I. Popa, Ultrason. Sonochem., 32, 191 (2016), doi: 10.1016/j.ultsonch.2016.03.009

19 Z. Wang, Z. He, Z. Zhao, S. Yi and J. Mu, Ultrason. Sonochem., 37, 47 (2017), doi: 10.1016/j.ultsonch.2016.12.028

20 A. Yeop, J. Sandanasamy, S. F. Pang, S. Abdullah, M. M. Yusoff et al., MATEC Web of Conferences 111, 02008, 2017, DOI: 10.1051/matecconf/20171110

21 NREL Laboratory Analytical Procedures for standard biomass analysis (https://www.nrel.gov/bioenergy/laboratory-analyticalprocedures.html).

22 V. L. Singleton and J. A. Rossi, Am. J. Enol. Vitic., 16 ,

144

(1965), http://www.ajevonline.org/content/16/3/144.full.pdf+ht $\mathrm{ml}$

S. Patil, S. Wankhade and V. Kamble, Int. J. Drug. Dev. Res., 6, 53 (2014).

24 C. E. Țebrencu, R. M. Cretu, G. R. Mitroi, E. Iacob and I. Ionescu, Phytochem. Rev., 14, 613 (2015), https://doi.org/10.1007/s11101-015-9410-8

25 C. H. Chan, R. Yusoff and G. C. Ngoh, Chem. Eng. Res. Des., 92, 1169 (2014), doi: 10.1016/j.cherd.2013.10.001

26 M. C. Wei and Y. C. Yang, Sep. Purif. Technol., 130, 182

(2014), https://doi.org/10.1016/j.seppur.2014.04.029

27 A. Bucić-Kojić, M. Planinić, S. Tomas, M. Bilić and D. Velić, J. Food Eng., 81, 236 (2007), https://doi.org/10.1016/j.jfoodeng.2006.10.027

28 L. Galvan d'Alessandro, K. Kriaa, I. Nikov and K. Dimitrov, Sep. Purif. Technol., 93, 42 (2012), https://doi.org/10.1016/j.seppur.2012.03.024

29 F. Chemat, Zill-e-Huma and M. K. Khan, Ultrason. Sonochem., $\quad \mathbf{1 8}, \quad 813 \quad$ (2011), 10.1016/j.ultsonch.2010.11.023

30 K. Vilkhu, R. Mawson, L. Simons and D. Bates, Food Sci. Emerg. Technol., 9, 161 (2008), DOI: 10.1016/j.ifset.2007.04.014

31 A. Meullemiestre, E. Petitcolas, Z. MaacheRezzoug, F. Chemat and S. A. Rezzoug, Ultrason. Sonochem., 28, $230 \quad$ (2016), doi: 10.1016/j.ultsonch.2015.07.022

32 Y. Chavan and R. S. Singhal, Innov. Food Sci. Emerg., 106,12013$)$, https://doi.org/10.1016/j.ifset.2012.10.001 